\title{
AMÉRICA DO SUL: reflexões contemporâneas sobre cooperação, democracia e desenvolvimento ${ }^{1}$
}

\author{
INTRODUÇÃO
}

\author{
Denise Vitale*
}

O presente Número Especial do Caderno CRH - O Brasil na América do Sul: cooperação, democracia e desenvolvimento - tem como objetivo proporcionar uma reflexão crítica sobre os avanços e desafios que o continente sul-americano enfrenta contemporaneamente em diversos campos temáticos. Nos últimos anos, sobretudo nas duas gestões do governo Lula (2003-2010), a agenda da política externa brasileira abriu espaço e deu prioridade para a chamada cooperação Sul-Sul, o que permitiu explorar as relações de cooperação para o desenvolvimento e estreitar laços com o chamado sul global. Conforme a estratégia adotada, o Brasil, considerado um país intermediário, poderia afirmar sua posição globalmente na medida em que fortalecesse os laços com os países da África, Ásia e América do Sul e Cari-

\footnotetext{
* Universidade Federal da Bahia (UFBA). Instituto de Humanidades, Artes e Ciências Prof. Milton Santos (IHAC) Programa de Pós-Graduação em Ciências Sociais (PPGCS) e Programa de Pós-Graduação em Relações Internacionais (PPGRI)

Rua Barão de Jeremoabo, s/n. Ondina. Cep: 40170115. Salvador - Bahia - Brasil. denisevitale@gmail.com

${ }^{1}$ A autora agradece os apoios concedidos por bolsas de Produtividade em Pesquisa (PQ2) do CNPQ (2016-2018) e Estágio Senior da CAPES (2015-2016) durante os quais este Número Especial foi organizado.
}

be, tanto por meio de relações bilaterais, como multilaterais.

É certo que os laços entre o Brasil e os demais países sul-americanos vêm de longa data, especialmente com os países do Cone Sul. A aproximação das relações entre o Brasil e a Argentina nos anos 1980 e a criação do Mercosul nos anos 1990 revelam que os esforços de aproximação e fortalecimento das relações internacionais do país para com seus vizinhos é uma política de Estado, sendo um traço marcante de governos tão diversos como os de José Sarney (1985-1989), Fenando Collor de Mello (19901992), Itamar Franco (1992-1993), Fernando Henrique Cardoso (1994-2002), Luiz Inácio Lula da Silva (2003 -2010) e Dilma Rousseff (2011-2016). Em todos esses governos, a política externa brasileira dedicou prioridade e manteve-se atenta às possibilidades e desafios latentes do bloco regional e da sua articulação com as demais organizações internacionais e países do continente.

No entanto, os dois governos Lula da Silva (2003-2010) deram forte ênfase à América do Sul, privilegiando a posição de destaque do Brasil no contexto continental. A criação 
da União de Nações Sul-Americanas (Unasul), que aglutinou pela primeira vez, em uma única organização, os doze países do continente, na busca de uma concertação política e de uma maior integração dos povos, foi a principal novidade institucional. A aposta na América do Sul, porém, foi inserida numa estratégia mais ampla de cooperação para o desenvolvimento, não mais centrada no eixo Norte-Sul, mas no paradigma Sul-Sul. Essa nova ênfase foi potencializada pelo fato de que a estratégia de uma cooperação Sul-Sul não se limitava ao continente sul-americano, mas orientava o incremento das relações com a África e com outros gigantes do mundo em desenvolvimento, como a Índia e, principalmente, a China. Ao mesmo tempo, a aposta no multilateralismo permitiu que a política externa desse período intensificasse o modelo da cooperação SulSul, tanto por meio de iniciativas específicas de concertação, como a criação do Fórum de Diálogo Índia, Brasil e África do Sul (IBAS), como também pela criação de grupos e coalizões dentro das organizações internacionais já existentes. A construção do G-20 no âmbito da Organização Mundial do Comércio (OMC) em 2003, durante a Conferência de Cancun, e a maior participação no G-20 financeiro, a partir da crise de 2008, são dois exemplos de um significativo protagonismo do Brasil entre os países emergentes e centrais no período.

A partir do governo Rousseff, mudanças no cenário político, jurídico e econômico do i Brasil e na conjuntura econômica internacional

$\dot{\sim}$ tenha teoricamente seguido os princípios de in今ิ serção internacional herdados do governo Lula,

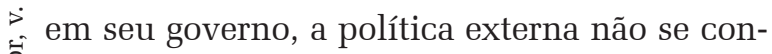
formou mais como eixo prioritário. Do ponto de vista econômico, os resultados negativos obtidos com a chamada nova matriz econômica, aliados à desaceleração da China e à contração da demanda por commodities, reduziram a disponibilidade de recursos para as relações Sul-
Sul. A diminuição de recursos teve impacto direto na manutenção do Brasil como promotor da cooperação Sul-Sul, seja no âmbito da cooperação técnica, seja na frente aberta para a internacionalização das empresas nacionais. Esse último ponto foi também afetado pela dinâmica da Operação Lava Jato, ainda em curso em meados de 2016, que, ao investigar casos de corrupção na Petrobrás, envolveu grandes empreiteiras brasileiras (várias com forte presença em países latino-americanos, caribenhos e africanos) em denúncias de irregularidades. Finalmente, às crises econômica e jurídica somou-se a crise política que marcou o sistema político, sobretudo após as manifestações de junho de 2013, e culminou com a abertura do processo de impeachment no Congresso.

No âmbito da América do Sul, a aposta nas relações Sul-Sul não ocorre imune a conflitos e tensões. Apesar do esforço na consolidação de uma identidade sul-americana e na busca de interesses comuns, o século XXI tem sido marcado por uma pluralidade de orientações político-ideológicas entre os países, muitas vezes antagônicas. Se, por um lado, a construção da Unasul buscou criar uma institucionalidade comum a todos os países, por outro lado, o contexto da governança é complexo, caracterizado por uma pluralidade de organizações, sobreposições e divisões. Países como Colômbia, Peru e Chile formaram, em 2013, a Aliança do Pacífico, calcada em um regionalismo aberto, contrastando com a estratégia de países como Venezuela, Equador e Bolívia, integrantes da Aliança Bolivariana para os Povos da Nossa América (Alba). Num terceiro eixo, situam-se os países do Mercosul - Brasil, Argentina, Paraguai e Uruguai e, a partir de 2012, a Venezuela - que, embora se contraponham à Aliança do Pacífico, tampouco integram a Alba (com a única exceção da Venezuela). Há, ainda, um quarto bloco importante, formado em 1969 pelos países andinos, a Comunidade Andina (CAN), que agrupa hoje o Peru, a Bolívia, a Colômbia e o Equador, todos com forte identidade andina, mas heterogêneos politicamente. 
Essas tensões e conflitos são agravados na medida em que a análise se abre para a complexidade interna de cada Estado, onde a fragmentação de interesses, grupos, identidades e visões de mundo é, sobremaneira, maior. É nessa dimensão que antagonismos e impasses nas áreas ambientais e de direitos humanos emergem, evidenciando as contradições não apenas entre soberanias estatais, mas entre interesses de um emaranhado de atores, que vão de governos e partidos políticos a empresas, povos indígenas, ambientalistas, migrantes, mulheres, igrejas e grupos religiosos, entre outros. Ao se olhar para a América do Sul como um território em disputa por tantos e tão diferentes atores, por meio de diversas lentes e diversos ângulos, revelam-se novas possibilidades de análise que buscam explicar algumas das questões contemporâneas que desafiam o continente.

Nesse contexto, os onze artigos reunidos no presente volume buscam contribuir para o debate das relações internacionais na região, em suas dimensões políticas, econômicas, ambientais, jurídicas e sociais. A proposta deste Número Especial é a de apresentar um panorama analítico de questões presentes na América do Sul contemporânea, a partir de uma perspectiva interdisciplinar e multitemática, abrangendo parte das muitas vozes, atores, interesses e identidades mencionados acima. Para tanto, a publicação conta com a participação de catorze autores, de diferentes nacionalidades e instituições acadêmicas, estimulados por esta organizadora a refletir sobre as questões da cooperação, do desenvolvimento e dos direitos humanos na América do Sul. ${ }^{2}$

O volume se inicia com o artigo de Carlos Soria "La Amazonía en el futuro de la América del Sur. Identificación de los ejes estratégicos socioambientales para la Coopera-

${ }^{2}$ As reflexões contidas neste volume visam a aprofundar temas que vêm sendo estudados e pesquisados no âmbito do Laboratório de Análise Política Mundial (LabMundo). Vale mencionar que três autores presentes nesta publicação integram o LabMundo e o projeto "Cooperação SulSul: um estudo sobre as dinâmicas socioeconômicas, políticas, científicas, culturais e ambientais na América do Sul a partir do caso brasileiro", desenvolvido entre 2011 e 2014 e financiado pela Fapesb e pelo CNPq. ción Sur-Sur”, que discute o papel estratégico da Amazônia na América do Sul, suas fissuras e tensões face ao equilíbrio entre desenvolvimento e sustentabilidade. Tendo como pano de fundo a implantação de megaprojetos como a Iniciativa para a Integração Regional da América do Sul (IIRSA) e a exploração sistemática de petróleo e gás, Soria analisa as possibilidades de transição para a economia verde, o impacto ambiental e a dramática questão indígena. O segundo texto, escrito por Breno Bringel e Alfredo Falero, "Movimientos sociales, gobiernos progresistas y Estado en América Latina: transiciones, conflictos y mediaciones”, apresenta uma reflexão ampla sobre a sociologia dos movimentos sociais na América Latina a partir das relações estabelecidas entre eles, os governos e os Estados da região.

Em seguida, os artigos se voltam para questões da governança institucional, analisando aspectos controversos do Mercosul, da Unasul e CAN. Andrea Ribeiro Hoffmann, no artigo "As Organizações Regionais e a promoção e proteção da democracia: reflexões a partir das práticas de intervenção democrática na América do Sul”, analisa o papel e o alcance das Organizações Regionais nas garantias democráticas, com foco na Organização dos Estados Americanos (OEA), no Mercosul e na Unasul. Tiago Nery, no texto "Unasul: a dimensão política do novo regionalismo sul-americano", explora o processo de construção da Unasul e suas possibilidades na consolidação de uma identidade sul-americana.

Na sequência, abre-se espaço para temas mais específicos de direitos humanos no âmbito sul-americano. Em "Puertas Abiertas: migrações regionais, direito e integração na Comunidade Andina de Nações e no Mercosul", José Sacchetta Ramos Mendes analisa as migrações intrarregionais a partir de uma análise comparada das bases legais do Mercosul e da CAN e das possibilidades de ação conjunta da pauta imigrantista. A agenda de direitos humanos, com ênfase na questão de gênero, é reforçada no artigo seguinte, de Olga Espinoza. Em "Mu- 
jeres privadas de libertad na América Latina: ¿Es posible su reinserción social?," a autora analisa a problemática do aumento do encarceramento feminino em países da América Latina e discute a eficácia das políticas públicas para a reinserção social.

A sétima contribuição, de Stefano Palestini, "Energía de baja intensidad: gobiernos, mercados e instituciones en el regionalismo energético de América del Sur", discute um tema central nas agendas governamentais sul-americanas e inerente a um processo exitoso de integração: a questão energética. $\mathrm{O}$ autor discute os déficits de implementação da política energética da região em função de divergências entre os governos sobre os modelos de integração.

Os três artigos seguintes fomentam o debate na área econômica, principalmente nos campos do desenvolvimento e da tributação. Elsa Sousa Kraychete, em "O Banco Nacional de Desenvolvimento Econômico e Social (BNDES) e a expansão de empresas brasileiras de construção civil para a América do Sul” analisa as possibilidades da cooperação brasileira na internacionalização das empresas, com o fomento do BNDES. O tema do desenvolvimento é ainda explorado por Albene Miriam Menezes Klemi e Roberto Goulart Menezes. No artigo "Brasil e Mercosul: rumos da integração na lógica do neodesenvolvimentismo (20032014)", os autores refletem sobre o processo de ๑ integração regional à luz de um contexto de goکั่ vernos considerados à esquerda e da presença กิ chinesa nas relações entre Brasil e Argentina.
A décima contribuição, "La relación entre tratados de inversión y tratados de doble tributación: el caso chileno", de Rodrigo Polanco Lazo e Felipe Yáñez Villanueva, aborda a temática da tributação no âmbito internacional, decisiva para as relações comerciais, a partir da experiência do Chile. Os autores refletem sobre os aspectos complementares e conflitantes de tipos diversos de tratados adotados no contexto chileno de integração global e suas consequências no âmbito multilateral das negociações comerciais.

Finalmente, o volume se encerra com o artigo de Iraneidson Santos Costa, "Amar e servir no sul da América: origem e articulação dos Centros Sociais Jesuítas.” A partir de uma análise histórica entre os anos 1950 e 1980, o autor discute a trajetória dos Centros de Investigação e Ação Social, marcada pela tensão entre o compromisso com a justiça social e a luta contra o comunismo no universo jesuíta.

Este Número Especial reúne, assim, onze estudos relevantes sobre as problemáticas contemporâneas da América do Sul nos campos da cooperação, democracia e desenvolvimento. É evidente, porém, que eles refletem apenas sobre uma parcela das tantas complexidades que o continente enfrenta. Que as análises aqui apresentadas abram novas perguntas e inquietações nos leitores, inspirando novas investigações.

Boa leitura!

\footnotetext{
Denise Vitale - Doutora em Direito. Professora do Instituto de Humanidades, Artes e Ciências Prof. Milton Santos (IHAC) e professora permanente do Programa de Pós-Graduação em Ciências Sociais (PPGCS) e do Programa de Pós-Graduação em Relações Internacionais (PPGRI) da Universidade Federal da Bahia (UFBA). Pesquisadora do Núcleo Direito e Democracia do Centro Brasileiro de Análise e Planejamento (CEBRAP), São Paulo. Tem experiência nas áreas de Direito, Ciência Política e Relações Internacionais, com ênfase em teoria política, teoria democrática, direitos humanos, meio ambiente, participação e controle social. Publicações recentes: O Brasil e a Cooperação Sul-Sul: dilemas e desafios na América do Sul. 1. ed. Salvador: Edufba, v. 1, 2015; Participatory governance and social protest in Brazil. Chance to Sustain Opinion Paper Series, v. 1, p. 12-13, 2014; Urban Chances in Brazil - Cities Report: Guarulhos, Salvador and Rio de Janeiro. Working Papers Chance 2 Sustain, v. 1, p. 1-38, 2013.
} 